\title{
Neural circuits underlying motor facilitation during observation of implied motion
}

\author{
Carmen Concerto ${ }^{1}$, Mohomad Al Sawah ${ }^{2}$, Carmenrita Infortuna ${ }^{2}$, David Freedberg ${ }^{3}$, Eileen Chusid ${ }^{2}$, \\ Eugenio Aguglia ${ }^{4}, \&$ Fortunato Battaglia ${ }^{1}$ \\ ${ }^{1}$ Department of Interprofessional Health Sciences \& Health Administration, School of Health and Medical Sciences, Seton Hall University, NJ, USA, \\ ${ }^{2}$ Pre-clinical sciences, New York College of Podiatric Medicine, New York, USA, ${ }^{3}$ Department of Art History Columbia University, and Italian Academy \\ for Advanced Studies, Columbia University, New York, USA, and ${ }^{4}$ Department of Clinical and Experimental Medicine, Psychiatry Unit, University of \\ Catania, Italy
}

\begin{abstract}
In the present study we used single and paired-pulse Transcranial Magnetic Stimulation (TMS) to evaluate the effect of implied motion on primary motor cortex microcircuits. We found that observation of the implied motion of a static image increases MEP amplitude and reduces short-interval intracortical inhibition $(\mathrm{SICl})$, without significant modulation of intracortical facilitation and sensory-motor integration. Our results add to the existing literature on the activation of the observation-execution matching system and describe a selective modulation of GABAergic cortical microcircuits during observation of implied motion.
\end{abstract}

\section{Keywords}

Implied motion, sensorymotor integration, $\mathrm{SICl}$, transcranial magnetic stimulation

\section{History}

Received 28 January 2015

Revised 18 March 2015

Accepted 24 March 2015

Published online 29 September 2015

\section{Introduction}

Implied motion (IM) indicates the perception of movement extracted from a representation that is static in nature using cues that generate directional information (Freyd 1987). Seminal recognition memory experiments using both static objects with progressive changes in their orientation (Hubbard 1995) and pictures of irreversible movements (Freyd 1983) clearly demonstrated perception of IM. Nevertheless, little is known about the cortical networks activated during this process. Previous works demonstrated that the processing of implied dynamic information from static images induces strong activation of the prototypical visual motion areas such as the medial temporal/medial superior temporal cortex (MT/MST) (Kourtzi and Kanwisher 2000; Krekelberg et al. 2003) (Senior et al. 2000; Fawcett et al. 2007) and the dorsal stream pathway (Krekelberg et al. 2005). Furthermore, experiments using single-pulse Transcranial Magnetic Stimulation (TMS) showed that observation of a photograph picturing humans performing an action increased the amplitude of motor-evoked potentials (MEPs) (Urgesi et al. 2010; Battaglia et al. 2011), suppresses $\mathrm{Mu}$ rhythm and modulates event-related potentials (Sbriscia-Fioretti et al. 2013) (Umilta et al. 2013). To the best of our knowledge, the modulation of intracortical inhibitory and facilitatory circuits

Correspondence: Dr. F. Battaglia, Seton Hall University. 400 South Orange Avenue, South Orange, NJ, 07079. Tel: 212.410.8072, Fax: 212.410.0940, E-mail: fortunato.battaglia@shu.edu in sensory-motor cortex during observation of IM still needs to be investigated.

Inhibitory and excitatory intracortical circuits can be explored using paired-pulse TMS. One can test, in this way, the effect of a conditioning TMS stimulus (CS) on a test stimulus and detect both short-intracortical-inhibition (SICI) and intracortical-facilitation (ICF) (Hallett 2000). Both SICI and ICF have been largely used to investigate GABAergic and glutamatergic cortical circuits in healthy subjects and in patients with neuropsychiatric diseases (Badawy et al. 2012; Ziemann 2013; Bunse et al. 2014).

Furthermore, using short- and long-latency afferent inhibition (SAI and LAI), it is possible to explore sensorimotor integration in humans. Peripheral nerve stimulation inhibits the motor cortex at short (SAI) and long (LAI) interstimulus intervals (ISI) (Tokimura et al. 2000). SAI is modulated by cholinergic and $\mathrm{GABA}_{\mathrm{A}}$ receptor (Di Lazzaro et al. 2007) while LAI is a cortical inhibitory phenomenon that needs to be further characterized (Pirio Richardson et al. 2009). These paradigms may be used to test the functional role of sensory information in human primary motor cortex (Asanuma and Rosen 1972).

The principal objective of this study was to investigate the specific circuits underlying motor facilitation during observation of a static image that implies motion.To achieve this goal, a comprehensive neurophysiological evaluation of intracortical excitability and sensorimotor integration was performed. We hypothesized that perception of a whole body in movement in a statue (such as a running abstract figure) 
would induce an overall increase in cortical excitability even in non-observed representations.

\section{Methods}

We studied 12 healthy volunteers (six men, aged $33 \pm 7.1$ years; mean $\pm \mathrm{SD}$ ). All the subjects were right-handed (Oldfield 1971). The protocol was approved by the Institutional Review Board of the New York College of Podiatric Medicine.

Each participant was seated on a comfortable chair in front of a computer monitor. The experiment consisted of eliciting MEP responses during three experimental conditions: (1) observation of a plus sign; (2) observation of a picture of the sculpture "Abstract Figure", by Oskar Schlemmer (1923) (Sculpture no-IM: implied motion); (3) observation of a picture of Umberto Boccioni's sculpture 'Unique Forms of Continuity in Space', (1913) (Sculpture-IM: implied motion). We selected Boccioni's sculpture because it so clearly sets out (as Boccioni himself and his fellow Futurists avowed) to give the impression of dynamism and speed by the forward motion on a figure in movement. On the contrary, in the case of Schlemmer's Abstract Figure, we have a more "static", representation on an abstract figure without arms (Figure 1).

To test our research hypothesis, we selected works of art without arms and recorded MEP from a hand muscle. The presentation of the conditions (blocks) was randomized. TMS stimuli were delivered $1000 \mathrm{~ms}$ after images presentation.

We used a $9 \mathrm{~cm}$ figure-of-eight coil connected with a monophasic Magstim 200 stimulator (Magstim 200; Whitland, Dyfed, UK). The coil was placed flat on the skull with the handle pointing backwards and $45^{\circ}$ away from the midline. It was placed at the optimal scalp position (hot spot) to elicit a maximal MEP in the contralateral Abductor Pollicis Brevis muscle (APB). Surface electromyography was monitored on a computer screen to ensure muscle relaxation. The signal was amplified (Digitimer D360, Letchworth Garden,
UK), filtered (band pass $20 \mathrm{~Hz}$ to $2.5 \mathrm{kHz}$ ), digitized at $5 \mathrm{kHz}$ (Power Micro1401, Cambridge Electronics Design, Cambridge, UK), and stored in a laboratory computer. Peakto-peak amplitudes of MEPs were measured.

We tested resting motor threshold (RMT) defined as the minimum stimulation intensity necessary to evoke MEPs of $50 \mu \mathrm{V}$ in $50 \%$ of 10 consecutive trials while the targeted hand was relaxed (Rossini et al. 1994). We then recorded MEP amplitude using a stimulation intensity of $110 \%$ RMT. SICI and ICF were tested by paired-TMS (Kujirai et al. 1993). SICI was induced with a CS set at $80 \%$ RMT delivered $2 \mathrm{~ms}$ before a test stimulus while for the induction of ICF the ISI was $10 \mathrm{~ms}$. The test stimulus was adjusted to induce consistently an MEP amplitude of $\sim 1 \mathrm{mV}$ (Godfrey et al. 2013). The different ISIs were randomly selected and twenty MEPs were recorded for each condition. SICI and ICF were expressed as percentage of conditioned/unconditioned MEP. Thus, values below $100 \%$ correspond to inhibition and values above $100 \%$ correspond to facilitation. Afferent inhibition was elicited by stimulating the medial nerve at the wrist with a Digitimer D-160 stimulator (Digitimer Ltd, Welwyn Garden City, Herts, UK). Stimulus intensity was adjusted to produce a slight thumb twitch. SAI and LAI were elicited using ISIs of $25 \mathrm{~ms}$ and $100 \mathrm{~ms}$, respectively. 20 unconditioned MEPs and 20 conditioned MEPs at each ISI were collected. The test stimulus was set to elicit $\sim 1 \mathrm{mV}$ MEP amplitude. SAI and LAI were expressed as percentage of conditioned/unconditioned MEP.

\section{Statistical analysis}

RMT and MEP amplitude were analyzed with ANOVA (main effects "Condition"). Paired pulse experiments (SICI, ICF and SAI, LAI) were analyzed by using two-way ANOVA (main effects "Stimulation" and "Condition"). Post-hoc test was used to test significance. All values in figures are expressed as mean \pm standard error (SE). Data were analyzed

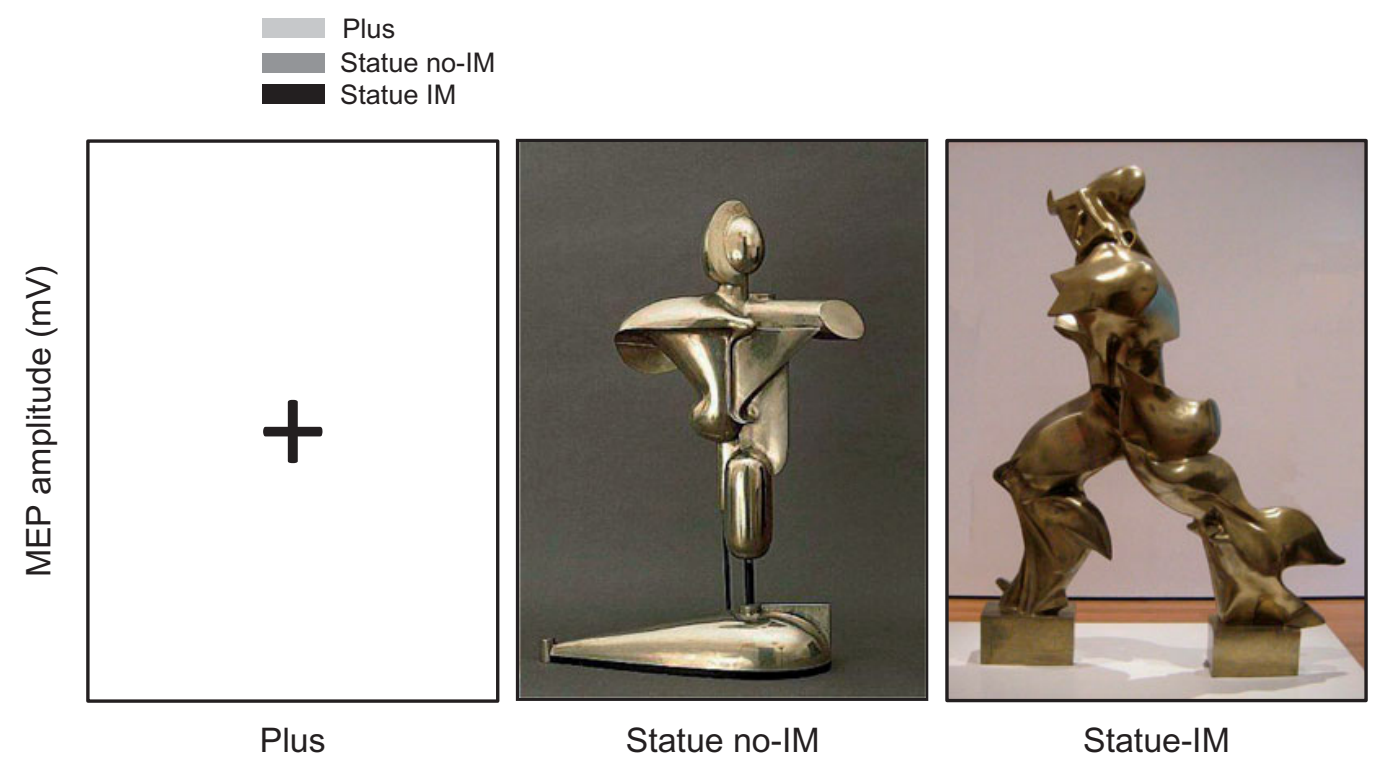

Figure 1 Experimental paradigm: TMS stimulation was performed during observation of a plus sign (plus), of a picture of the sculpture Abstract Figure, 1923 by Oskar Schlemmer (Sculpture no-IM: implied motion) and during observation of a picture of the sculpture Unique Forms of Continuity in Space, 1913 by Umberto Boccioni (Sculpture IM: implied motion). 
using SPSS Version 20 (IBM Corporation, Chicago, IL, USA). Statistical significance was set at 0.05 .

\section{Results}

RMT recorded in the right $\mathrm{APB}$ did not differ between conditions (Plus: $43 \pm 2.6 \%$; Statue no-IM: $45 \pm 2.2 \%$, StatueIM: $44 \pm 2.6 \%, \mathrm{~F}_{(2,33)}=0.15, p=0.7$ ) (data not showed). We next tested the effect of IM on MEP size. Observation of the picture of the Statue-IM induced an increase in MEP size (Plus: $0.43 \pm 0.03 \mathrm{mV}$; Statue no-IM: $0.49 \pm 0.04 \mathrm{mV}$; StatueIM: $0.63 \pm 0.04 \mathrm{mV}, \mathrm{F}_{(2,33)}=5.6, p=0.008$ ) (Figure 2).

We then tested intracortical excitability and sensory-motor integration. In the paired-pulse paradigm TMS, the mean stimulus intensities used to obtain an MEP of $\sim 1 \mathrm{mV}$ (TS) was $51 \pm 3.8 \%$ for the Plus, $54 \pm 3.5 \%$ for the Statue no-IM, and $52 \pm 3.6 \%$, for Statue-IM. Two-way ANOVA showed a main effect for "Stimulation" $\left(\mathrm{F}_{(1,66)}=169.8, p<0.0001\right)$ indicating that $2 \mathrm{~ms}$ ISI induced inhibition while $10 \mathrm{~ms}$ ISI induced facilitation, and a main effect "Condition", $\left(\mathrm{F}_{(2,66)}=3.4, p=0.03\right)$ without a significant "Stimulation", $\mathrm{X}$ "Condition" interaction $\left(\mathrm{F}_{(2,66)}=0.7, p=0.4\right)$. Post-hoc analysis indicated that the amount of SICI was not different between the observation of the Plus sign and Statue no-IM ( $p=0.5)$ while during observation of the Statue-IM was significantly smaller compared to the Plus sign $(p=0.01)$ and with the Statue no-IM ( $p=0.001)$ (Figure 3). On the contrary, the amount of ICF was similar between the conditions (Plus: $151 \pm 7.3 \%$; Statue no-IM: $145.3 \pm 8.5 \%$; Statue no-IM: $159.9 \pm 11 \% ; p>0.05$ ) (Figure 3). Observation of the Statue IM image did not modulate sensorimotor integration (SAI: Plus: $76.2 \pm 4.4 \%$; Statue no-IM: $79.5 \pm 4.7 \%$, Statue IM: $80.7 \pm 4.1 \%$; LAI: Plus: $75.1 \pm 4.1 \%$; Statue no-IM: $74.1 \pm$ $3.3 \%$, Statue IM: $77.3 \pm 4.7 \%$. "Stimulation', $\left(\mathrm{F}_{(1,66)}=0.9\right.$, $p=0.3)$; “Condition', $\left(\mathrm{F}_{(2,66)}=0.3, p=0.7\right)$; Stimulation' $\mathrm{X}$ “Condition', interaction $\left(\mathrm{F}_{(2,66)}=0.1, p=0.8\right)$ (Figure 4).

\section{Discussion}

The present study investigated whether IM information from static image of a sculpture influences intracortical excitability and sensorimotor integration. Our findings indicate that observation of an image with IM increases MEP size and reduces SICI. Furthermore, results for SAI and LAI suggest that sensorimotor integration seems not to be affected.

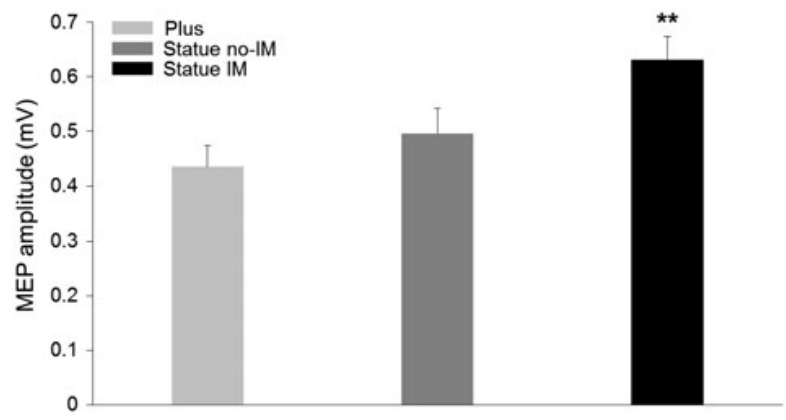

Figure 2. Observation of implied motion increased MEP size. Error bars represent standard error of the mean. $* *<0.01$. TMS: Transcranial Magnetic Stimulation.
As previously reported (Urgesi et al. 2006), observation of IM increases MEP amplitude. We replicated these findings. Furthermore, in our study MEPs were recorded in the APB muscle even though the representation of arms in Unique Forms of Continuity in Space is limited at best. It is possible that observation of so humanoid and dynamic figure with wing-like forms might have conveyed an illusory perception of arm-hand movement recruiting, in this way, circuits normally activated during observation of actual hand actions (Fadiga et al. 1995; Sbriscia-Fioretti et al. 2013). We can
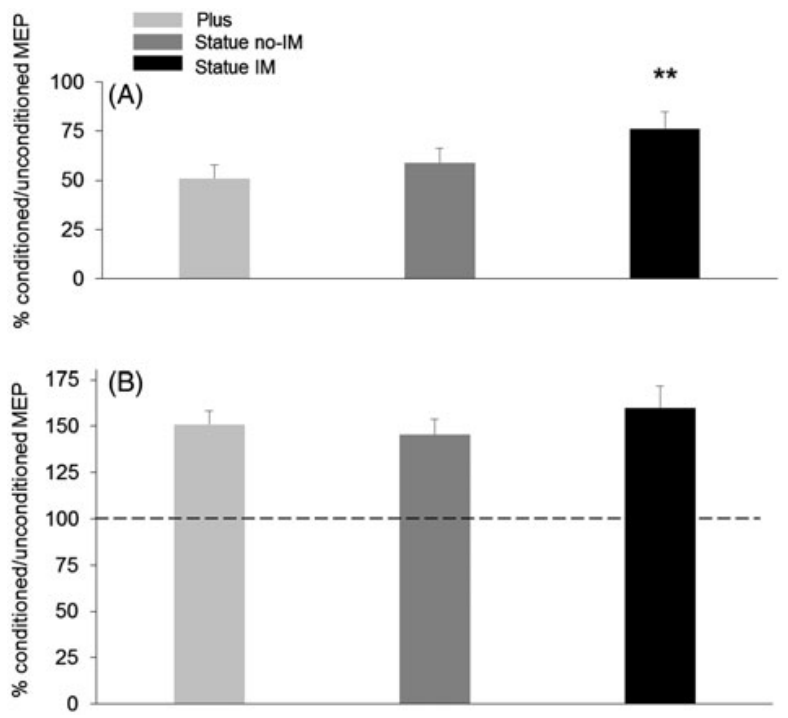

Figure 3. (A) SICI and (B) ICF. Observation of implied motion induced a decrease in the amount of SICI. There is no significant difference between conditions for ICF. Error bars represent standard error of the mean. $* *<0.01$. SICI: short-interval intracortical inhibition; ICF: intracortical facilitation.
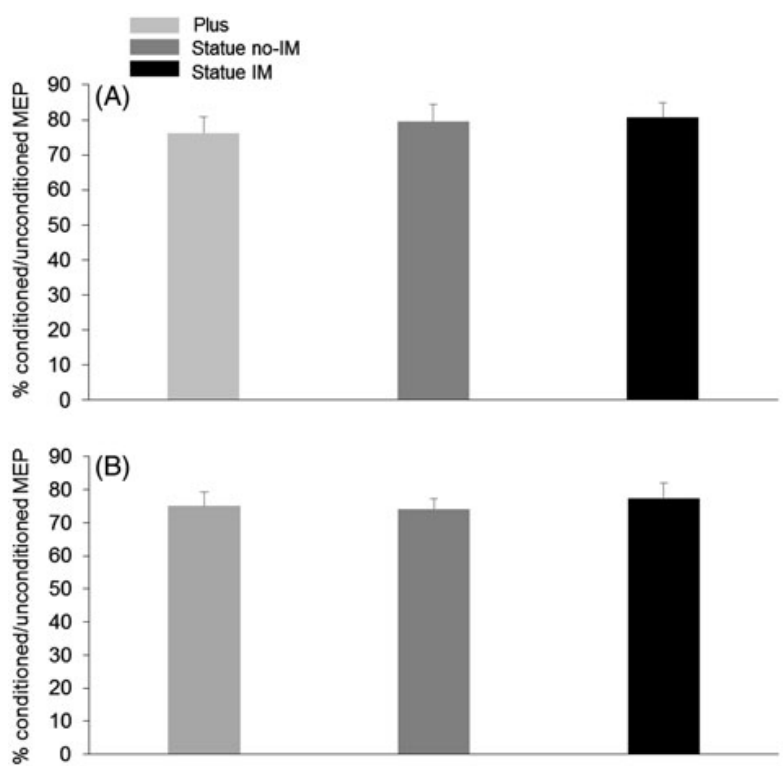

Figure 4. (A) SAI and (B) LAI. There is no significant difference between conditions. Error bars represent standard error of the mean. SAI: short-afferent inhibition; LAI: long-afferent inhibition. 
speculate that observation of highly dynamic images induce overall facilitation in primary motor cortex even in representations that have no direct role in the execution of that action. General motor cortex activation may be due to the aesthetic content of the images, by enhancing the viewer's attention and therefore the tendency to grasp and manipulate (Kawabata and Zeki 2004; Urgesi et al. 2006). We showed that the observation of IM reduces SICI and induces a non-significant increase in ICF. It is likely that the activity of intracortical GABAergic microcircuits (Di Lazzaro et al. 2007) is decreased during observation of IM. This might be due either to the activation of the observation-execution matching system or to the activation of motor imagery networks that, as previously reported, have a similar modulatory effect on SICI (Patuzzo et al. 2003). SICI and SAI are TMS parameters that test two distinct inhibitory circuits in human motor cortex (Sanger et al. 2001; Di Lazzaro et al. 2007). Interestingly, IM did not affect SAI indicating a selective modulation of inhibitory circuits with specific $\mathrm{GABA}_{\mathrm{A}}$ receptor subtypes ( $\alpha 2$ - or $\alpha 3$-subunit) (Di Lazzaro et al. 2007).

In the present paper, we added to the knowledge of the cortical mechanisms underlying the perception of implied motion by demonstrating a selective modulation of cortical GABA-ergic microcircuits. Our results will be relevant in designing more effective, evidence-based programs involving visual art as a potential treatment for patients with both motor and cognitive deficits.

Furthermore, to generalize our findings future studies will be needed to investigate these aspects of intracortical excitability and the role of gender (Proverbio et al. 2009) in the case of observation of both moving objects and more purely abstract art forms.

\section{Declaration of interest}

The authors report no conflicts of interest.

\section{References}

Asanuma H, Rosen I. 1972. Functional role of afferent inputs to the monkey motor cortex. Brain Res 40:3-5.

Badawy RA, Loetscher T, Macdonell RA, Brodtmann A. 2012. Cortical excitability and neurology: insights into the pathophysiology. Funct Neurol 27:131-145.

Battaglia F, Lisanby SH, Freedberg D. 2011. Corticomotor Excitability during Observation and Imagination of a Work of Art. Frontiers In Human Neuroscience 5:79.

Bunse T, Wobrock T, Strube W, Padberg F, Palm U, Falkai P, Hasan A. 2014. Motor cortical excitability assessed by transcranial magnetic stimulation in psychiatric disorders: a systematic review. Brain Stimul 7:158-169.

Di Lazzaro V, Pilato F, Dileone M, Profice P, Ranieri F, Ricci V, Bria P, Tonali PA, Ziemann U. 2007. Segregating two inhibitory circuits in human motor cortex at the level of GABAA receptor subtypes: a TMS study. Clin Neurophysiol 118:2207-2214.

Fadiga L, Fogassi L, Pavesi G, Rizzolatti G. 1995. Motor facilitation during action observation: a magnetic stimulation study. J Neurophysiol 73:2608-2611.
Fawcett IP, Hillebrand A, Singh KD. 2007. The temporal sequence of evoked and induced cortical responses to implied-motion processing in human motion area V5/MT+. Eur J Neurosci 26:775-783.

Freyd JJ. 1983. The mental representation of movement when static stimuli are viewed. Percept Psychophys 33:575-581.

Freyd JJ. 1987. Dynamic mental representations. Psychol Rev 94: 427-438.

Godfrey SB, Lum PS, Chan E, Harris-Love ML. 2013. Cortical effects of repetitive finger flexion- vs. extension-resisted tracking movements: a TMS study. J Neurophysiol 109:1009-1016.

Hallett M. 2000. Transcranial magnetic stimulation and the human brain. Nature 406:147-150.

Hubbard TL. 1995. Cognitive representation of motion: evidence for friction and gravity analogues. J Exp Psychol Learn Mem Cogn 21: 241-254.

Kawabata H, Zeki S. 2004. Neural correlates of beauty. J Neurophysiol 91:1699-1705.

Kourtzi Z, Kanwisher N. 2000. Activation in human MT/MST by static images with implied motion. J Cogn Neurosci 12:48-55.

Krekelberg B, Dannenberg S, Hoffmann KP, Bremmer F, Ross J. 2003. Neural correlates of implied motion. Nature 424:674-677.

Krekelberg B, Vatakis A, Kourtzi Z. 2005. Implied motion from form in the human visual cortex. Journal of neurophysiology 94:4373-4386.

Kujirai T, Caramia MD, Rothwell JC, Day BL, Thompson PD, Ferbert A, Wroe S, Asselman P, Marsden CD. 1993. Corticocortical inhibition in human motor cortex. J Physiol 471:501-519.

Oldfield RC. 1971. The assessment and analysis of handedness: the Edinburgh inventory. Neuropsychologia 9:97-113.

Patuzzo S, Fiaschi A, Manganotti P. 2003. Modulation of motor cortex excitability in the left hemisphere during action observation: a singleand paired-pulse transcranial magnetic stimulation study of self- and non-self-action observation. Neuropsychologia 41:1272-1278.

Pirio Richardson S, Bliem B, Voller B, Dang N, Hallett M. 2009. Longlatency afferent inhibition during phasic finger movement in focal hand dystonia. Exp Brain Res 193:173-179.

Proverbio AM, Riva F, Zani A. 2009. Observation of static pictures of dynamic actions enhances the activity of movement-related brain areas. PLoS One 4:e5389.

Rossini PM, Barker AT, Berardelli A, Caramia MD, Caruso G, Cracco RQ, Dimitrijevic MR, Hallett M, Katayama Y, Lucking CH, et al. 1994. Non-invasive electrical and magnetic stimulation of the brain, spinal cord and roots: basic principles and procedures for routine clinical application. Report of an IFCN committee. Electroencephalogr Clin Neurophysiol 91:79-92.

Sanger TD, Garg RR, Chen R. 2001. Interactions between two different inhibitory systems in the human motor cortex. J Physiol 530:307-317.

Sbriscia-Fioretti B, Berchio C, Freedberg D, Gallese V, Umilta MA. 2013. ERP modulation during observation of abstract paintings by Franz Kline. PLoS One 8:e75241.

Senior C, Barnes J, Giampietro V, Simmons A, Bullmore ET, Brammer M, David AS. 2000. The functional neuroanatomy of implicit-motion perception or representational momentum. Curr Biol 10:16-22.

Tokimura H, Di Lazzaro V, Tokimura Y, Oliviero A, Profice P, Insola A, Mazzone P, Tonali P, Rothwell JC. 2000. Short latency inhibition of human hand motor cortex by somatosensory input from the hand. J Physiol 523 Pt 2:503-513.

Umilta MA, Berchio C, Sestito M, Freedberg D, Gallese V. (2012). Abstract art and cortical motor activation: an EEG study. Frontiers In Human Neuroscience 6:311.

Urgesi C, Maieron M, Avenanti A, Tidoni E, Fabbro F, Aglioti SM. 2010. Simulating the future of actions in the human corticospinal system. Cereb Cortex 20:2511-2521.

Urgesi C, Moro V, Candidi M, Aglioti SM. 2006. Mapping implied body actions in the human motor system. J Neurosci 26:7942-7949.

Ziemann U. 2013. Pharmaco-transcranial magnetic stimulation studies of motor excitability. Handb Clin Neurol 116:387-397. 